\title{
Результаты U-Pb датирования цирконов из риолитов Совдозерского домена Ведлозерско-Сегозерского зеленокаменного пояса Карельского кратона
}

\author{
Гоголев М.А., Чаженгина С.Ю., Рыбникова 3.П., Назарова Т.Н., Светов С.А. \\ Институт геологии Карельского научного иентра РАН, Петрозаводск, mag-333@таil.ru
}

Аннотация. Выполнено U-Pb датирование цирконов из дайки кислого состава, секущей мезоархейский базальтовый комплекс Совдозерского домена Ведлозерско-Сегозерского зеленокаменного пояса Карельского кратона. Получены следующие результаты: по семи зернам циркона (соотношение Th/U 0.7-0.8) установлен возраст формирования дайки риолитов равный 2966 10 млн. лет, который может рассматриваться как верхнее временное ограничении для базальтов Совдозерского домена. Таким образом, полученные значения существенно удревнили общепринятый интервал коматиит-базальтового вулканизма в ВедлозерскоСегозерском зеленокаменном поясе. По другим четырем зернам циркона, претерпевшим частичную перекристаллизацию, которая выражена в виде лоскутной зональности, наличии вторичных минералов во включениях в цирконе и низком уровне $\mathrm{Th} / \mathrm{U}(0.1-0.2)$ получены значения возрастов от 2830 до 2430 млн. лет, которые отражают вероятное время воздействия на домен сдвиговых деформаций и флюидную проработку пород.

Ключевые слова: риолиты, геохимия, U-Pb датирование, циркон, зеленокаменный пояс.

\section{$\mathrm{U}-\mathrm{Pb}$ dating of zircons from rhyolites in the Sovdozero domain, Vedlosero-Segosero greenstone belt, Karelian craton}

\author{
Gogolev M.A., Chazhengina S.Y., Rybnikova Z.P., Nazarova T.N., Svetov S.A. \\ Institute of Geology, Karelian Research Centre, RAS, mag-333@mail.rul
}

\begin{abstract}
This paper reports $\mathrm{U}-\mathrm{Pb}$ dating of zircons from felsic dyke, which is intrusive into basalt series of the Sovdozero domain, Vedlosero-Segosero greenstone belt, Karelian craton. The seven zircons with the Th/U ratio of 0.7-0.8 give the age of 2966 $\pm 10 \mathrm{Ma}$, which is supposed to indicate the upper intercept age of basalts from the Sovdozero domain. Therefore, the obtained results demonstrate that the formation of komatiite-basalt rocks in the Vedlosero-Segosero greenstone belt occurred earlier compared with the data reported in the previous studies. Four zircons with the signs of recrystallization marked by patchy zoning and inclusions of secondary minerals along with the low values of $\mathrm{Th} / \mathrm{U}$ ratio ca. 0.1-0.2 give the lower age varying from 2830 to $2430 \mathrm{Ma}$ and corresponding to the later tectonic deformation and fluid transformation of the rocks.
\end{abstract}

Key words: rhyolites, geochemistry, $\mathrm{U}-\mathrm{Pb}$ dating, zircon, greenstone belt.

\section{Введение}

Геохронологическое изучение коматиит-базальтовых ассоциаций докембрия является не тривиальной задачей. Это связано как с отсутствием в породах минералов -геохронометров, так и существенной метаморфической проработкой вулканитов, вызывающей полную потерю первичного минерального парагенеза, что затрудняет использование Sm-Nd метода исследований. На протяжении многих лет основными объектами для $\mathrm{U}-\mathrm{Pb}$ датирования (по цирконам) мафитовых ассоциаций являются секущие комплекс кислые дайки и внутриформационные терригенные осадки.

В данной работе показаны результаты геохронологического изучения цирконов из дайки риолитового состава, секущей базальтовый разрез Совдозерского домена. Важность данного объекта для геохронологического изучения определяется хорошей сохранностью, разнообразием мезоархейского коматиит-базальтового комплекса в домене, а также наличием лишь оценочных данных по времени его формирования (Svetov et al., 2001).

\section{Геологическое положение и петрографическая характеристика риолитов}

Совдозерский домен расположен в северо-западной части Ведлозерско-Сегозерского зеленокаменного пояса и приурочен к системе озер Совдозеро-Хейзьярви (рис. 1). Протяженность домена составляет 20 км в меридиональном направлении. Мезоархейские породные ассоциации Совдозер- 
ского домена подразделяют на две толщи: сложенную ультраосновными-основными вулканитами и осадочную, сформированную углеродсодержащими филлитами, железистыми кварцитами, туфами и туффитами дацитов, песчаниками (Чернов и др., 1970). Породный комплекс с востока ограничен гранитогнейсами, плагиогнейсогранитами, плагиомикроклиновыми и микроклиновыми гранитами, а с запада толщей ятулийских образований (Светов, 2005).

Коматиит-базальтовая ассоциация в Совдозерском домене представлена нижней пачкой базальтов мощностью около 300 м и верхней толщей коматиитов мощностью 600 м. Контакты между пачками тектонические, а сам разрез имеет слайдерный характер (Светов, 2005). Интрузивные комплексы структуры представлены маломощными дайками дацит-риолитового состава, высокомагнезиальными габброидами и телами ультрамафитов.

В основании разреза базальты представлены подушечными, массивными, иногда миндалекаменными лавовыми потоками с редкими прослоями туфового материала. В разрезе доминируют подушечные лавы с характерным дифференцированным строением подушек: наличием централь-

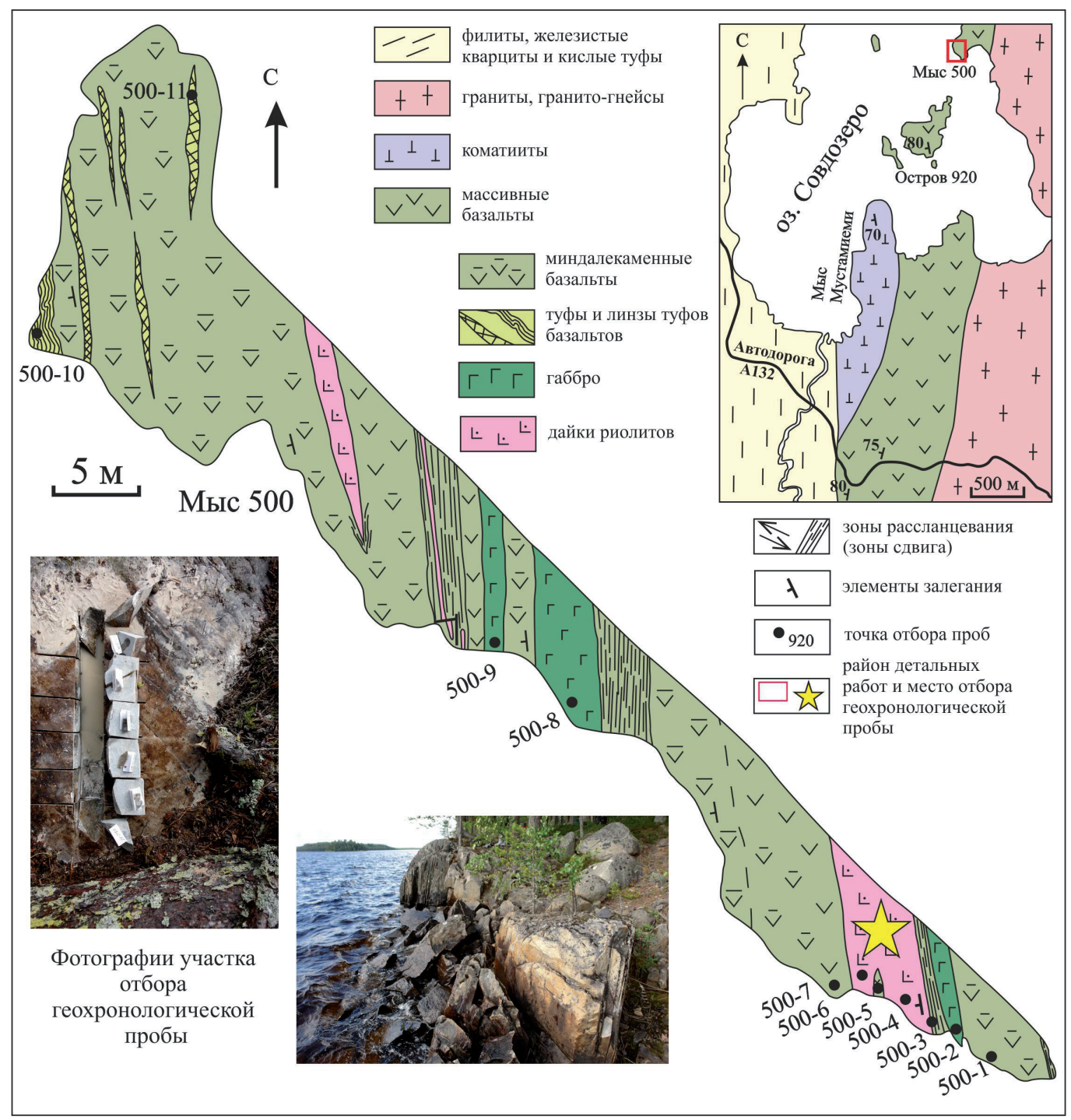

Рис. 1. План геологического строения Совдозерской структуры и строение детального участка - Мыс 500 (Рыбникова 3.П., Гоголев М.А., Назарова Т.Н., с использованием материалов Чернова В.М. Желтой звездой показан участок отбора геохронологической пробы.

Fig. 1. Detailed scheme of the Mys 500 sampling area (Rybnikova Z.P., Gogolev M.A., Nazarova T.N., additionally using the data of Chernov V.M) with inset of schematic geological map of the Sovdozero domain. The yellow asterisk marks the geochronological sample location. 
ных миндалин и/или вариолитовых линз и зон глобул в ядрах (Светов, 2005). Вблизи тектонических контактов с коматиитовой толщей породы сильно рассланцеваны, превращены в актинолиттремолитовые сланцы.

Дайки риолитового состава, мощностью до 5 м, секущие базальтовую толщу, выявлены в районе участка Мыс «500» и автодороги А132, но, при этом, не обнаружены в коматиитовом комплексе структуры (Мыс Мустаниеми). Мыс «500» (рис. 1) был выбран как основной участок работ для геохронологического изучения дайки риолитового состава (рис. 1, проба 500-4).

\section{Результаты U-Pb датирования риолитов}

Изученная дайка на участке Мыс «500» имеет мощность от 4 до 4.5 м, субвертикальное залегание, сечет лавовый поток миндалекаменных базальтов (рис. 1, проба 500-4) и характеризуется массивной текстурой и микрозернистой структурой. В западном контакте непосредственно рассекает лавовый поток базальтов и имеет тонкую зону закалки. В восточном контакте дайка контактирует через зону рассланцевания с телом высокомагнезиальных габброидов, которые рассматриваются как комагматичные базальтам. В ядерной части дайковогого тела установлены ксенолиты базальтового состава.
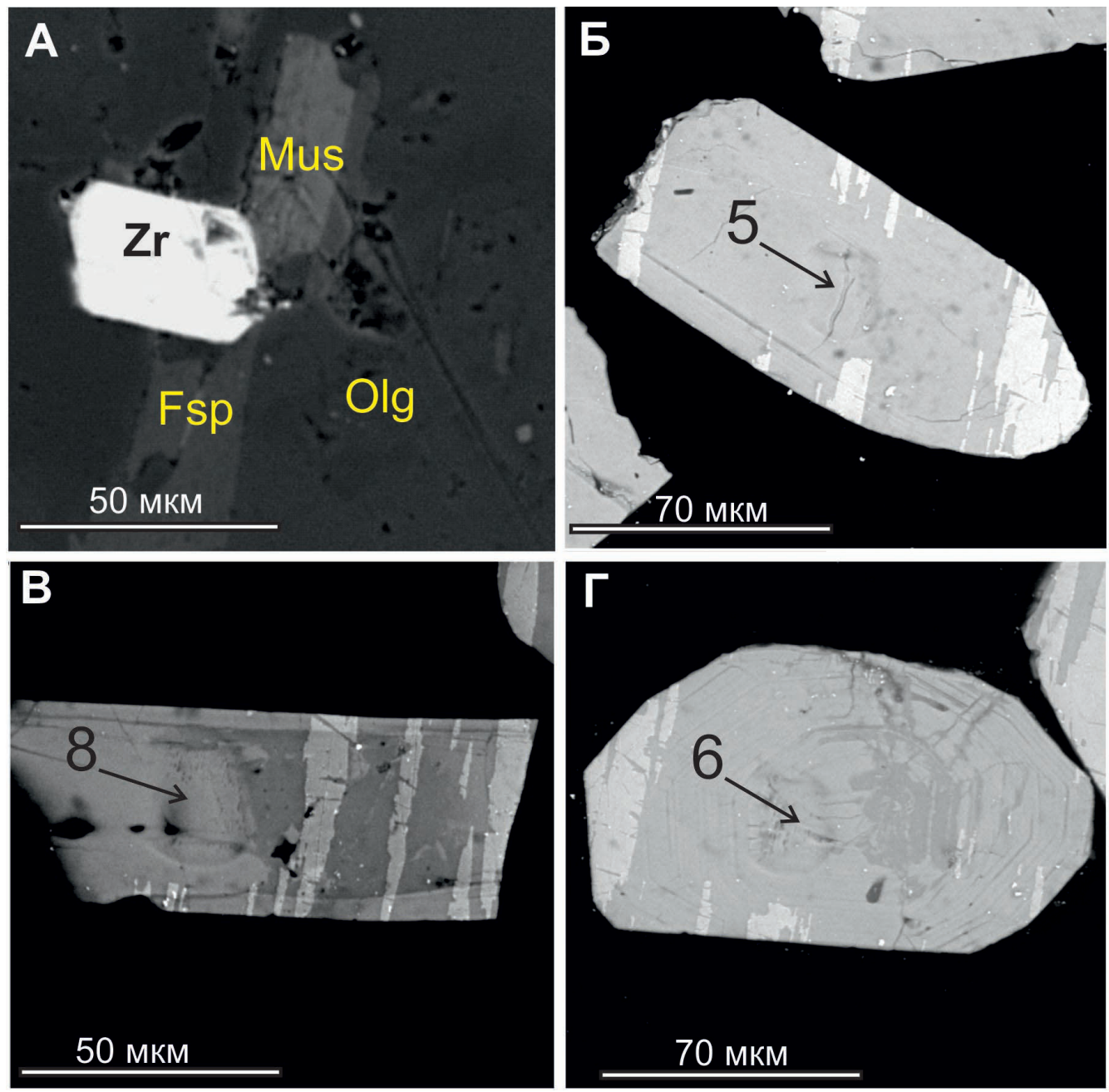

Рис. 2. Микрофотографии цирконов из дайки риолитов Совдозерского домена в отраженных электронах: а) шлиф, Zr - циркон, Mus - мусковит, Fsp - калиевый полевой шпат, Olg - олигоклаз; б, в, г) шайба после съемки на ионном микрозонде SHRIMP-II (стрелками показан центр анализируемого участка зерна).

Fig. 2. BSE-images of zircons from rhyolite dykes in the Sovdozero domain a) rock thin section, $\mathrm{Zr}-\mathrm{zircon}$, Mus - muscovite, Fsp - potassium feldspar, Ort - oligoclase; б, в, г); zircons subjected to the SHRIMP analysis (arrows mark the center of the grain studied area). 

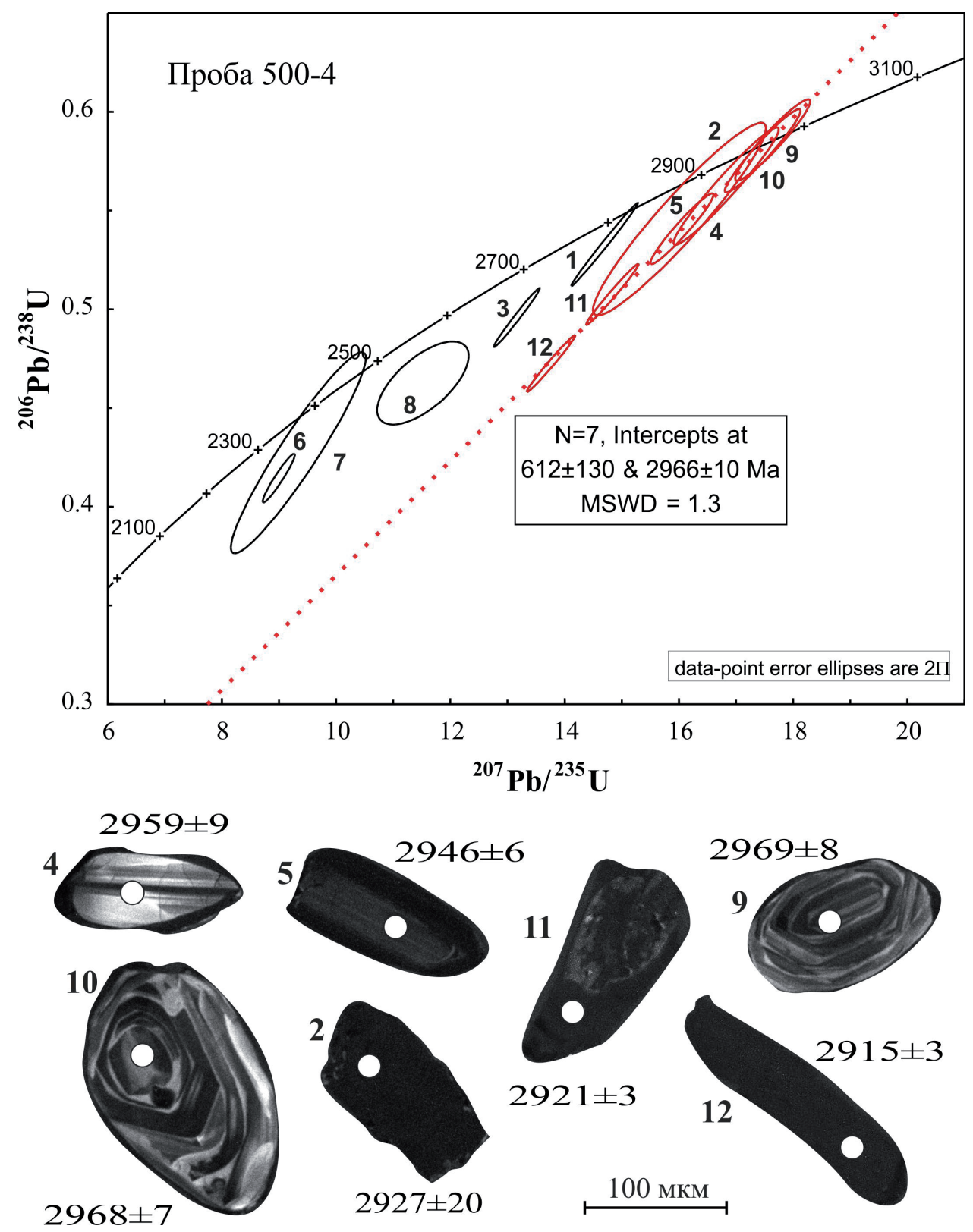

Рис. 3. Диаграмма с конкордией для цирконов из дайки риолитов Совдозерского домена и их микрофотографии в катодолюминесценции. Кружками отмечены анализируемые участки и показан ${ }^{207} \mathrm{~Pb} /{ }^{206} \mathrm{~Pb}$ возраст данного участка.

Fig. 3. Concordia diagram and CL images for zircons from rhyolites of the Sovdozero domain. The circles mark the studied areas with their ${ }^{207} \mathrm{~Pb} /{ }^{206} \mathrm{~Pb}$ ages.

В минеральном плане дайка выполнена кварцем, олигоклазом $\left(\mathrm{An}_{15-20}\right)$ и мусковитом. По плагиоклазу развивается биотит и эпидот, а по мусковиту калиевый полевой шпат. Акцессорные и рудные минералы представлены апатитом, сфеном, цирконом, рутилом, галенитом и баритом. В аналитическом центре Института геологии КарНЦ РАН с помощью сканирующего электронного микроскопа VEGA II LSH (Tescan) с энергодисперсионным микроанализатором INCA Energy 350 (Oxford instruments) были детально изучены зерна цирконов в породе, которые по морфологии могут быть разделены на две группы. Первая группа представлена однофазными, незональными (без ядер) зернами призматического габитуса размером до 40 мкм (рис. 2, а и б), которые находятся в кварцплагиоклаз-мусковитовом матриксе. 
Вторая группа представлена зернами циркона неправильной или овальной формы размером до 50 мкм, имеющих лоскутную зональность (рис. 2 в, г), которая, вероятнее всего, маркирует частичную перекристаллизацию зерен (Corfu et al., 2003). Данный вид цирконов встречается в кварцплагиоклаз-мусковитовом матриксе, а их более мелкие разновидности (до 10 мкм) нередко находятся в виде включений в эпидоте.

Для $\mathrm{U}-\mathrm{Pb}$ геохронологического изучения дайки из ее центральной части была отобрана проба массой 3 кг, из которой была выделена монофракция циркона. В результате выделения было получено около 100 зерен цирконов, из которых были отобраны наиболее представительные 30 зерен размером 50-100 мкм и проведено их изучение методами катодолюминесценции (КЛ) и сканирующей электронной микроскопией. В итоге 12 зерен цирконов были отобраны для определения их возраста на вторично-ионном микрозонде высокого разрешения (SHRIMP-II, ВСЕГЕИ).

По морфологии и особенностям состава из отобранной серии зерен к первой группе можно отнести около 15 агрегатов, в которых отсутствует выраженная зональность (рис. 2, б), но характерна внутрифазовая неоднородность, проявленная в виде единичных включений первичных магматических минералов, таких как мусковит, кварц и F-апатит. В КЛ излучении данные цирконы имеют полосчатые оболочки. Важной характеристикой является внутрикристаллическое распределение Th и $\mathrm{U}$, потому что отношение $\mathrm{Th} / \mathrm{U}>0.5$ отражает его магматический генезис (Hoskin, Schaltegger, 2003). Так для данной группы Th/U равно 0.7-0.8. Возраст, полученный по данной фракции циркона, paвен 2966 10 млн. лет (рис. 3).

Ко второй группе цирконов, для которой характерна лоскутная зональность, можно отнести также 15 зерен (рис. 2, в, г). Установлено, что химическая неоднородность, проявленная в возникновении лоскутной зональности, связана с тем, что светлые центральные зоны зерен содержат микропримесь Hf, а темные зоны - Na, Ca и Al. Кроме того, в этих цирконах выявлены включения вторичных и акцессорных минералов: калиевого полевого шпата, биотита, F-апатита, монацита, платиноидов, торита и эпидота (аскагенита?). В КЛ излучении эти зерна темные. Отношение $\mathrm{Th} / \mathrm{U}$ для большинства цирконов данной группы составляет в среднем 0.1-0.2. Для них получен следующий геохронологический интервал: от 2830 до 2430 млн. лет (рис. 3), который, вероятно, отражает период тектонической реактивизации пород, время воздействия на домен сдвиговых сил, вызвавших локальную перекристаллизацию пород и минеральных индивидов. Такие процессы отмечены и в прочих доменах Водлозерского террейна. Так, для значительной части изученных цирконов из пород данного домена по данным (Арестова и др., 2017) свойственно развитие по трещинам в них лоскутной зональности, что в свою очередь приводит к омолаживанию зерен циркона, в которых произошла замена магматических на метаморфические характеристики.

\section{Выводы}

Изучение цирконов риолитовой дайки, секущей базальтовый комплекс Совдозерского домена Ведлозерско-Сегозерского зеленокаменного пояса Карельского кратона, позволило оценить возраст ее кристаллизации, а также интервал проявления метаморфизма в Совдозерском домене. В результате по 7 зернам циркона получен возраст кристаллизации дайки риолитов $2966 \pm 10$ млн лет, который может рассматриваться как верхнее ограничении периода формирования базальтов Совдозерского домена. Таким образом, полученные значения существенно удревнили общепринятый интервал коматиит-базальтового вулканизма в Ведлозерско-Сегозерском зеленокаменном поясе. По другим четырем зернам циркона, претерпевшим частичную перекристаллизацию, получены значения в интервале от 2830 до 2430 млн. лет, которые отражают вероятное время сдвиговых деформаций и поздней метаморфической (флюидной) проработки вулканитов.

Работа выполнена в рамках темы НИР Института геологии КарНЦ РАН.

\section{Литература}

1. Арестова Н.А., Чекулаев В.П., Кучеровский Г.А., Егорова Ю.С., Скублов С.Г. О соответствии геологических данных и результатов датирования архейских пород U-PB методом по циркону на примере Карельской провинции Балтийского щита // Региональная геология и металлогения. 2017. № 71. С. 35-52. 
2. Светов С.А. Магматические системы зоны перехода океан - континент в архее восточной части Фенноскандинавского щита. Петрозаводск: КарНЦ РАН. 2005. 230 с.

3. Чернов В.М., Инина К.А., Горьковец В.Я., Раевская М.Б. Вулканогенные железисто-кремнистые формации Карелии. Петрозаводск. Изд-во: Карелия. 1970. 285 с.

4. Corfu F.J. M., Hanchar P.W., Hoskin O. Atlas of zircon textures // Rev. Mineral. Geochim. 2003. 53. P. $468-500$. https://doi.org/10.2113/0530469.

5. Hoskin P.W.O., Schaltegger J.M. The composition of zircon and igneous and metamorphic petrogenesis // Reviews in mineralogy and geochemistry. 2003. 53. P. 27-62. https://doi.org/10.2113/0530027.

6. Svetov S.A., Svetova A.I., Huhma H. Geochemistry of the komatiite-tholeiite rock association in the Vedlozero-Segozero archean greenstone belt, Central Karelia // Geochemistry International. 2001. 39 (suppl. 1). P. 24-38. 